${ }^{1}$ Department of Periodontology, School of Dentistry, Veiga de Almeida University (UVA), Brazil.

${ }^{2}$ Department of Periodontology, School of Dentistry, Rio de Janeiro State University (UERJ), Brazil.
Corresponding author:

Antonio Canabarro, DDS, PhD Department of Periodontology, Veiga de Almeida University (UVA), Rua Ibituruna 108, casa 3, sala 201. CEP 20271-020, Tijuca,

Rio de Janeiro, RJ, Brazil.

Fax: +55-21-25748871

E-mail: canabarro@uva.br

Conflict of interest: The authors declare that they have no conflict of interest

Received: September 27, 2018

Accepted: June 14, 2019

\section{Putative periodontal bacteria in clinically healthy and diseased sites of periodontitis patients}

\author{
Carlos Eduardo Barros ${ }^{1}$, Vivian Siqueira ${ }^{1}$, Dennis \\ Carvalho ${ }^{1}$, Antonio Canabarro ${ }^{1,2, *}$
}

Aim: The aim of this study was to compare the microbial profile of subgingival sites in Periodontitis $(\mathrm{Pd})$ patients and healthy ones. Methods: Eighteen patients with $\mathrm{Pd}$ and 18 gender-matched healthy controls were selected. Subgingival samples were collected from three types of sites: 1) healthy site of healthy subjects (probing pocket depth $(P P D) \leq 3 m m, C G), 2$ ) healthy site of $P d$ patients (PPD $\leq 3 \mathrm{~mm}$, PG-C) and 3) diseased site (PPD > $3 \mathrm{~mm}$ ) of the same $\mathrm{Pd}$ patients (PG-T). All sites were subjected to microbial analysis for the detection of 40 bacterial species by the "Checkerboard DNA-DNA hybridization" technique. Results: It was observed a great diversity of bacteria in all patients evaluated. The sites from the Pd groups (PG-T and PG-C) showed a higher overall count of the studied bacteria than those of the CG group, especially from Green, Orange, and Red complexes. Also, PG-T showed a higher prevalence of Red complex bacteria than CG. Individual pathogens, such as Porphyromonas gingivalis, Treponema denticola and Treponema socranskii were detected in higher levels and/or prevalence in Pd than in control patients. However, it was not observed any difference between PG-T and PG-C. Conclusion: Pd patients showed higher prevalence and counts of some putative periodontal bacteria, especially from the red complex, than control ones, regardless of the severity of their sites.

Keywords: Periodontitis. Bacteria. Molecular biology. 


\section{Introduction}

Gingivitis and periodontitis are diseases that affect many people worldwide. While gingivitis is considered a reversible marginal inflammation, periodontitis causes irreversible destruction of the supporting tissues of the teeth, resulting in the formation of periodontal pockets and eventually in tooth loss ${ }^{1}$.

In periodontal disease, microorganisms adhered to the tooth surface in the biofilm and can release a large number of inflammatory mediators in the adjacent periodontal tissues. These microorganisms cause inflammation and, in many cases destroy of these tissues ${ }^{2}$.

Periodontal pockets can harbor over 500 bacterial species that are mostly resident species. However, a part of these are potentially pathogenic ${ }^{3}$ and may result, under certain circumstances, in an infection due to the excessive release of inflammatory mediators ${ }^{4,5}$

In the 1990s, the theory that biofilm contained specific bacteria gained strength. Six microbial complexes with distinct characteristics seem to be involved in the formation of subgingival biofilm in sequential phases. The red complex microorganisms, Porphyromonas gingivalis, Tannerella forsythia, and Treponema denticola, are potential etiologic agents of periodontitis ${ }^{6-9}$.

Although these bacteria allegedly have an important role in the pathogenesis of periodontal disease, there does not seem to be a single causative agent in inflammatory periodontal diseases. Gram-positive bacteria, anaerobes, and facultative organisms, as well as viruses and fungi, have also been associated with periodontitis ${ }^{10,11}$. In fact, periodontal pathogens can also be detected in healthy individuals although at low levels ${ }^{12}$.

Large communities of microorganisms, collectively called microbiomes, inhabit the surfaces of our body ${ }^{13}$, including teeth. The diversity and abundance of these communities are huge ${ }^{13}$, and this situation is no different in the mouth. Recent studies indicate that the participation of specific pathogens is not as obvious as we previously thought when considering both periodontitis and dental caries. Both diseases appear to result from an imbalance among the constituents of bacterial communities, resulting in dysbiosis ${ }^{14}$.

Therefore, identifying certain bacteria in individuals with and without periodontal disease in healthy and diseased sites using modern techniques based on DNA identification may be an interesting way to understand the etiology of Periodontitis in greater depth.

The study aimed to assess the microbial profile of healthy and diseased sites of patients with Periodontitis using the Checkerboard DNA-DNA hybridization technique and to compare it to data from control subjects.

\section{Materials and Methods}

\section{Patients}

Eighteen patients of both sexes were enrolled in this controlled cross-sectional study. The following inclusion criteria, based on the criteria of the 2017 World 
Workshop on the Classification of Periodontal and Peri-Implant Diseases and Conditions ${ }^{15}$ were used: if interdental clinical attachment loss $(C A L)$ is detectable at $\geq 2$ non-adjacent teeth, or Buccal or oral CAL $\geq 3 \mathrm{~mm}$ with probing pocket depth (PPD) $>3 \mathrm{~mm}$ is detectable at $\geq 2$ teeth (Periodontitis Group - PG). They were compared to 18 gender-matched healthy control patients of both sexes without Periodontitis (No CAL, Control Group - CG).

All participants were recruited as they came to the clinic for treatment and met the inclusion criteria of the study. After anamnesis, all patients signed an informed consent form. The study was approved by the ethics committee on human research, under number 1397046.

The exclusion criteria were: periodontal treatment for at least a year, pregnancy, lactation, use of prostheses, medical conditions that could affect the existence of bacteria in periodontal tissues (e.g., HIV, antibiotic or non-steroidal anti-inflammatory therapy for at least six months).

\section{Sample collection}

After the clinical examination, cotton-rolls and saliva-ejector were used to keep teeth dry. Subgingival samples were collected from three types of sites: 1) healthy site of healthy subjects (CG), 2) healthy site of subjects with Periodontitis (PG-C) and 3) diseased site (PPD > 3mm) of Periodontitis subjects (PG-T). PG-T and PG-C sites were selected from the same patients. Subgingival biofilm samples were collected using one sterile paper point, size 45 (Dentisply, Petropolis, Rio de Janeiro, Brazil) for each tooth. Only one site per tooth was studied. The most severe site was chosen for analysis in PG-T, while healthy sites were randomly selected in PG-C and CG. Paper points were introduced into periodontal pockets (diseased sites) or gingival sulcus (control sites) for at least 30 seconds.

The samples were immediately placed into individual plastic tubes containing $150 \mu \mathrm{L}$ of TE buffer solution (10mM Tris-HCL (Invitrogen Life Technologies, Carlsbad, CA, USA), 1 mM EDTA (Labsynth Products for Laboratories Ltd., Diadema, SP Brazil), $\mathrm{pH}$ 7.6), and then 100 ul of $0.5 \mathrm{M} \mathrm{NaOH}$ (Labsynth) was added so that the bacterial DNA remained viable for a longer period of time. These plastic tubes were previously labeled with the individual's name, date, and site; and, after collection, were stored under refrigeration at $-20^{\circ} \mathrm{C}$ until the samples were analyzed by the DNA-DNA hybridization checkerboard technique for bacterial strains.

\section{Checkerboard DNA-DNA hybridization}

Counts of 40 bacterial species were determined using the checkerboard DNADNA hybridization technique ${ }^{8}$. The analyses were performed at the Microbiology Laboratory of Guarulhos University as previously described ${ }^{16,17}$. Table 1 presents the 40 reference strains used to develop the DNA probes according to the bacterial complexes ${ }^{6,9}$.

The readings of the radiographic films were carried out by a single trained examiner, calibrated and blind to the objectives of the study. Readings were performed on different days to verify the results. Each signal produced by a given plaque sample probe 
Table 1. List of the bacterial strains used for the preparation of DNA probes. The species are grouped by bacterial complexes. ${ }^{6,17}$

\begin{tabular}{|c|c|c|c|}
\hline Species & Strain & Species & Strain \\
\hline Blue Complex & \multicolumn{3}{|c|}{ Orange Complex (cont.) } \\
\hline Actinomyces gerencseriae & $23860^{a}$ & Fusobacterium nucleatum ssp nucleatum & $25586^{a}$ \\
\hline Actinomyces israelii & $12102^{\mathrm{a}}$ & $\begin{array}{l}\text { Fusobacterium nucleatum ssp } \\
\text { polymorphum }\end{array}$ & $10953^{\mathrm{a}}$ \\
\hline Actinomyces naes/undii 1 & $12104^{a}$ & Fusobacterium nucleatum ssp vincentii & $49256^{a}$ \\
\hline Actinomyces naeslundii 2 & $43146^{a}$ & Fusobacterium periodonticum & $33693^{\mathrm{a}}$ \\
\hline Purple Complex & & Parvimonas micra & $33270^{\mathrm{a}}$ \\
\hline Actinomyces odontolyticus & $17929^{a}$ & Prevotella intermedia & $25611^{a}$ \\
\hline Veillonella parvula & $10790^{\mathrm{a}}$ & Prevotella nigrescens & $33563^{\mathrm{a}}$ \\
\hline Yellow Complex & & Streptococcus constellatus & $27823^{a}$ \\
\hline Streptococcus gordonii & $10558^{a}$ & Red Complex & \\
\hline Streptococcus intermedius & $27335^{a}$ & Tannerella forsythia & $43037^{a}$ \\
\hline Streptococcus mitis & $49456^{a}$ & Porphyromonas gingivalis & $33277^{\mathrm{a}}$ \\
\hline Streptococcus oralis & $35037^{a}$ & Treponema denticola & $\mathrm{B} 1^{\mathrm{b}}$ \\
\hline Streptococcus sanguinis & $10556^{a}$ & Other species & \\
\hline Green Complex & & Eubacterium saburreum & $33271^{\mathrm{a}}$ \\
\hline \multirow{2}{*}{$\begin{array}{l}\text { Aggregatibacter } \\
\text { actinomycetemcomitans } a+b\end{array}$} & \multirow{2}{*}{$\begin{array}{l}43718^{a} \\
29523^{a}\end{array}$} & Gemella morbillorum & $27824^{\mathrm{a}}$ \\
\hline & & Leptotrichia buccalis & $14201^{\mathrm{a}}$ \\
\hline Capnocytophaga gingivalis & $33624^{a}$ & Neisseria mucosa & $19696^{\mathrm{a}}$ \\
\hline Capnocytophaga ochracea & $33596^{a}$ & Prevotella melaninogenica & $25845^{a}$ \\
\hline Capnocytophaga sputigena & $33612^{\mathrm{a}}$ & \multirow{2}{*}{ Propionibacterium acnes I + II } & $11827^{a}$ \\
\hline Eikenella corrodens & $23834^{a}$ & & $11828^{a}$ \\
\hline Orange Complex & & Selenomonas noxia & $43541^{a}$ \\
\hline Campylobacter gracilis & $33236^{a}$ & Streptococcus anginosus & $33397^{a}$ \\
\hline Campylobacter rectus & $33238^{a}$ & Treponema socranskii & $S 1^{b}$ \\
\hline Campylobacter showae & $51146^{a}$ & & \\
\hline Eubacterium nodatum & 33099a & & \\
\hline
\end{tabular}

${ }^{\text {a } A T C C}$ (American Type Culture Collection); ${ }^{\text {F }}$ Forsyth Institute

was compared in intensity to the signal produced by the same probe in the two control lines containing $10^{5}$ and $10^{6}$ bacteria. The number 0 was recorded when no signal was detected; 1 was equivalent to a less intense signal than the control of $10^{5}$ cells; 2 was equivalent to $10^{5}$ cells; 3 was between $10^{5}$ and $10^{6}$ cells; 4 was equal to or approximately $10^{6}$ cells, and 5 was more than $10^{6}$ cells. These logs were used to determine the levels of different species investigated in the different samples under evaluation. The sensitivity of the assay allowed the detection of 10,000 units of each bacterial species studied by adjusting the concentration of each DNA probe. The number of bacteria in each site was estimated according to the signal intensity number: $0=0$, $1=10,000,2=100,0003=500,000,4=1,000,000$ and $5=10,000,000$. 


\section{Statistical analysis}

Statistical evaluation was performed using SPSS Statistics version 17 (IBM, Armonk, NY, USA). Initially, the normal distribution of data was checked with the Kolmogorov-Smirnov test. Subsequently, the non-parametric Kruskal-Wallis test and the chi-square test $(\chi 2)$ were used to analyze the prevalence and proportion of the positive sites for different types of bacteria, i.e., sites with values $\geq 1$, and the nonparametric Mann-Whitney test was used to evaluate the differences in the bacteria count among the three types of sites. The analysis unit was the patient. The significance level of $5 \%$ was established for the remaining analyzes.

The sample size was calculated using the percentage of sites with $P$. gingivalis as the primary outcome variable. PG-T showed $80 \%$ and CG $30 \%$ of sites colonized by these bacteria based on a pilot study (data not shown). Considering a statistical power of $85 \%$ and a $95 \%$ confidence level, a total of 18 individuals per group was needed.

\section{Results}

Eighteen patients, 12 female and 6 male, aged between 30 and 70 years old (mean age $51.50 \pm 14.24)$, with a mean CAL of $4.72( \pm 1.40) \mathrm{mm}$ (Periodontitis group - PG), and 18 gender-matched periodontally and systemically healthy control patients (control group - CG), aged between 20 and 30 years old (mean age $24.65 \pm 3.12$ ) were included in this study (Table 2).

Table 2. Characteristics of studied individuals.

\begin{tabular}{lcc}
\hline Characteristics & PG $(\mathbf{n = 1 8})$ & CG $(\mathbf{n = 1 8})$ \\
\hline Age (Mean and SD) & $51.5(14.2)$ & $24.7(3.1)^{\star}$ \\
\hline Gender: Male / Female & $6 / 12$ & $6 / 12$ \\
\hline Number of teeth (Mean and SD) & $21.4(6.3)$ & $24.5(5.6)^{\star}$ \\
\hline PPD (mm, Mean and SD) & $4.5(1.8)$ & - \\
\hline CAL (mm, Mean and SD)** & $4.7(1.4)$ & - \\
\hline
\end{tabular}

*Statistical difference between groups $(p<0.05)$. PPD = Periodontal Pocket Depth; CLA = Clinical Attachment Loss. $\mathrm{PG}=$ Periodontitis group; $\mathrm{CG}=$ Control group.

Diseased (PG-T) and healthy sites (PG-C) from the same Periodontitis patients and healthy sites from control ones (CG) were analyzed using the Checkerboard DNA-DNA hybridization technique.

The overall prevalence of the bacterial species evaluated did not differ among groups $(p=0.131)$. PG-T, PG-C, and CG showed $72 \%, 64 \%$ and $49 \%$ of positive sites, respectively.

The most prevalent bacteria in PG-T were T. socranskii (100\%) and Actinomyces naeslundii 1 (94\%). In the PG-C, the most prevalent bacteria were Actinomyces gerencseriae (100\%) and T. denticola (94\%). Finally, in the CG the most prevalent were Fusobacterium nucleatum ssp vincentii (84\%) and A. naeslundii (77\%) (Figure 1).

On evaluating each bacterium individual, PG-T and PG-C groups compared to CG showed higher prevalence of: $A$. gerencseriae (PG-T (94\%)=PG-C (100\%)>CG (28\%), $p<0.001)$, 


\section{Positive sites (\%)}

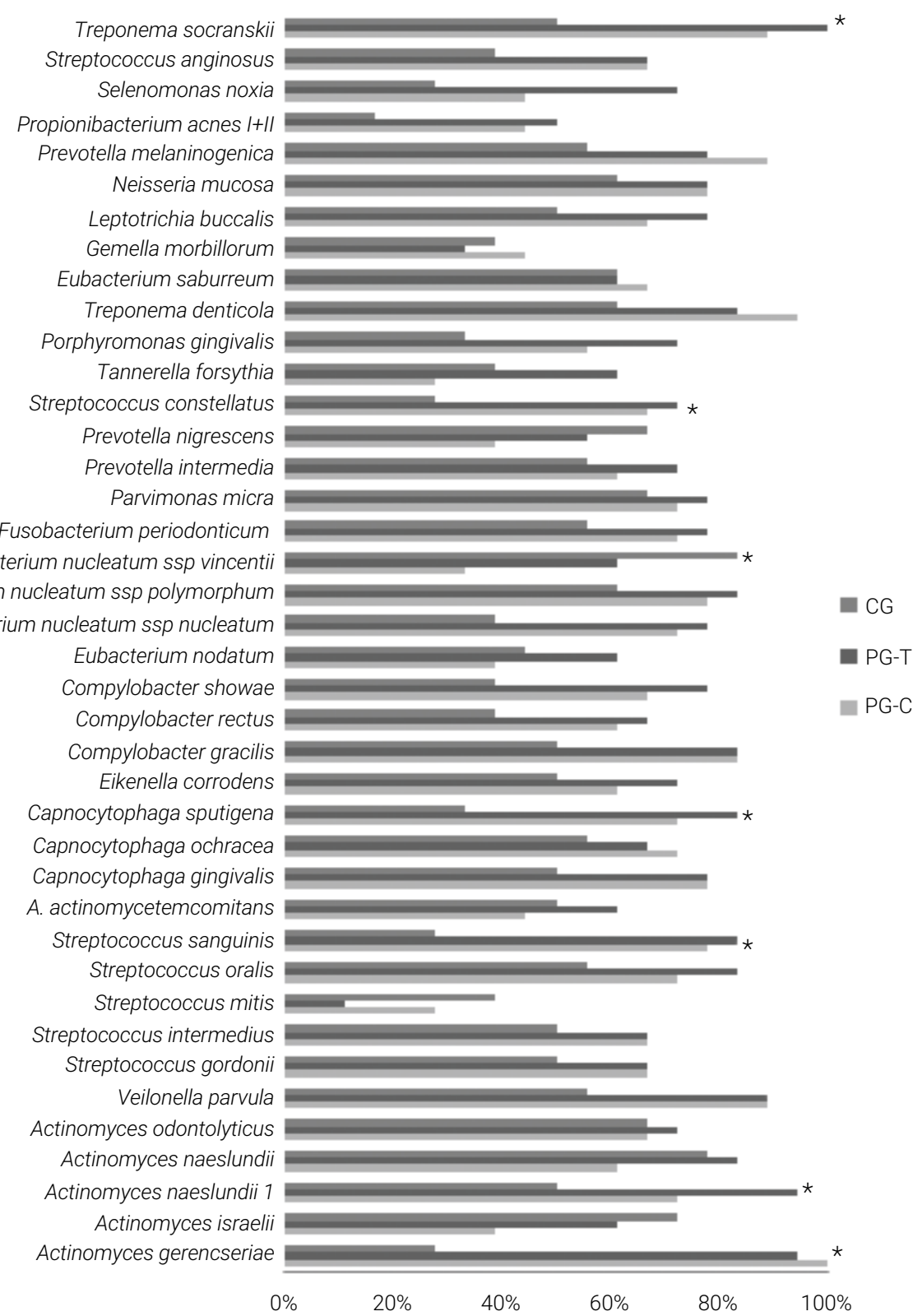

Figure 1. Prevalence of the 40 bacterial species evaluated in the three groups (Healthy - Control, CG; Periodontitis - Test, PG-T and Periodontitis - Control, PG-C). Statistically significant differences among groups were evaluated by Chi-Square Test $(*)$.

A. naeslundii 1 (PG-T (94\%)=PG-C (72\%)>CG (50\%), $p=0.012)$, Streptococcus sanguinis (PG-T (83\%)=PG-C (78\%)>CG (28\%), p= 0.001), Capnocytophaga sputigena (PG-T (83\%)=PG-C (72\%)>CG (33\%), p= 0.005), Streptococcus constellatus (PG-T (72\%)=PG-C $(67 \%)>C G(28 \%), p<0.014)$ and T. socranskii (PG-T (100\%)=PG-C (89\%)>CG (50\%), p<0.001) (Figure 1). F. nucleatum ssp vincentii was the only bacteria statistically more prevalent in CG and PG-T than in PG-C (CG (84\%)= PG-T (61\%)>PG-C (33\%), p< 0.009) (Figure 1). 
Comparison of positive sites and bacterial complexes demonstrated a statistical difference in the Red complex only (Figure 2). A higher number of positive sites were found in diseased sites of Pd patients compared to CG (PG-T $(72 \% \pm 31)>C G(44 \pm 36)$, $p=0.027 ; P G-T(72 \% \pm 31)=P G-C(59 \% \pm 27), p=0.171$ and PG-C $(59 \% \pm 27)=C G(44 \pm 36)$, $p=0.226)$.

\section{Positive sites (\%)}

Treponema socranskii
Streptococcus anginosus
Selenomonas noxia
Propionibacterium acnes $1+1 /$
Prevotella melaninogenica
Neisseria mucosa
Leptotrichia buccalis
Gemella morbillorum
Eubacterium saburreum
Treponema denticola
Porphyromonas gingivalis
Tannerella forsythia
Streptococcus constellatus
Prevotella nigrescens
Prevotella intermedia
Parvimonas micra

Fusobacterium nucleatum ssp vincentii Fusobacterium nucleatum ssp polymorphum

Fusobacterium nucleatum ssp nucleatum

Eubacterium nodatum

Compylobacter showae Compylobacter rectus Compylobacter gracilis

Eikenella corrodens Capnocytophaga sputigena Capnocytophaga ochracea Capnocytophaga gingivalis A. actinomycetemcomitans Streptococcus sanguinis Streptococcus oralis Streptococcus mitis Streptococcus intermedius Streptococcus gordonii Veilonella parvula Actinomyces odontolyticus Actinomyces naes/undii Actinomyces naes/undii 1 Actinomyces israelii Actinomyces gerencseriae

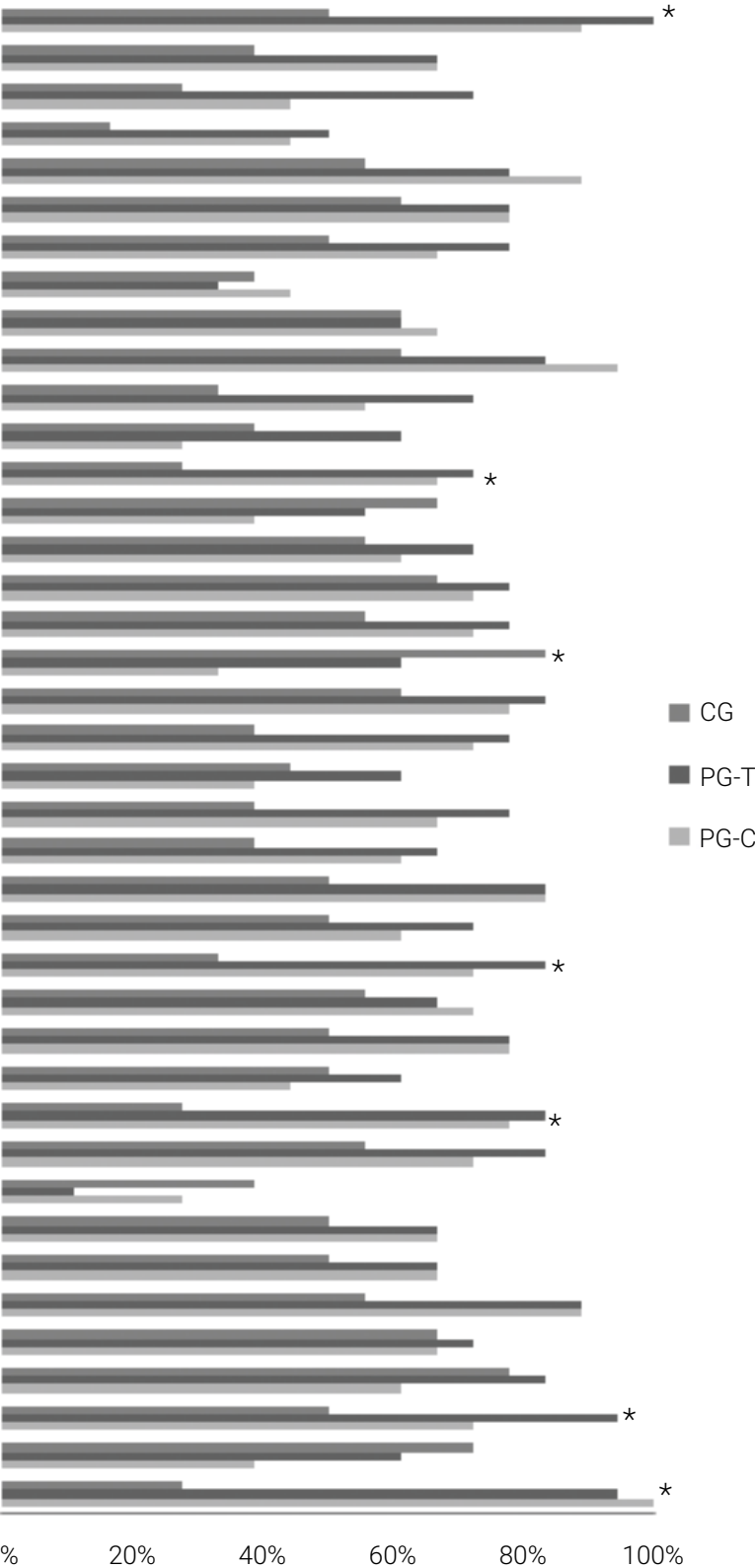

Figure 2. Proportion (mean \% and DP) of bacterial complexes in different groups (Healthy - Control, CG; Periodontitis - Test, PG-T and Periodontitis - Control, PG-C). Statistically significant differences among groups were evaluated by Kruskal-Wallis followed by Mann-Whitney Test $\left(^{*}\right)$. 
The overall mean count of the bacterial species evaluated differed among groups $(p=0.002)$. PG-T, PG-C, and CG showed $2.35 \times 10^{5}( \pm 2.25), 1.85 \times 10^{5}( \pm 2.25)$ and $0.45 \times 10^{5}( \pm 0.50)$ of bacteria, respectively (PG-T=PG-C>CG).

When evaluating the mean count of each bacteria, no significant difference was found between the PG-T and PG-C groups. However, at the PG-T group sites compared to the $\mathrm{CG}$ ones there were significantly more $\left(\times 10^{5} \pm \mathrm{DP}\right)$ : A. gerencseriae (5.28 \pm 4.22 vs $0.18 \pm 0.38, p<0.001)$, Veillonella parvula (3.15 \pm 3.82 vs $0.06 \pm 0.05$, $p=0.001)$, S. sanguinis ( $0.78 \pm 1.58$ vs $0.03 \pm 0.05, p<0.001)$, Capnocytophaga gingivalis (2.24 \pm 2.87 vs $0.15 \pm 0.31, p=0.008)$, C. sputigena $(1.75 \pm 2.72$ vs $0.18 \pm 0.38$, $\mathrm{p}=0.006)$, F. nucleatum ssp nucleatum (4.62 \pm 4.33 vs $0.19 \pm 0.38, p=0.002)$, P. gingivalis $(13.02 \pm 31.86$ vs $0.08 \pm 0.23, p<0.011)$, T. denticola (3.79 \pm 3.98 vs $0.41 \pm 0.48$, $\mathrm{p}=0.008)$, Leptotrichia buccalis $(9.62 \pm 22.99$ vs $0.25 \pm 0.41, p=0.008)$ and $T$. socranskii (3.91 \pm 3.48 vs $0.30 \pm 0.45, p<0.001$ ) (Figure 3).

All the bacteria above mentioned were also in higher number in the PG-C group compared to the CG sites, except $P$. gingivalis ( $0.86 \pm 2.32$ vs. $0.08 \pm 0.23, P G-C=C G$, $\mathrm{p}<0.118$ ) (Figure 3).

Comparison of mean bacterial count and complexes demonstrated that there were more Green $(p=0.012)$, Orange $(p=0.001)$, Red $(p=0.002)$ complexes and Others bacteria $(p=0.010)$ in PG-T and PG-C than in CG (PG-T=PG-C>CG) (Figure 4).

\section{Discussion}

Several studies have demonstrated the relationship between colonization of specific microorganisms and the presence and/or severity of periodontal disease. The bacteria involved in deep periodontal pockets are mainly of the red complex such as $P$. gingivalis, T. denticola and T. forsythia (formerly Bacteroides forsythus) ${ }^{18}$. Moore et al. ${ }^{19}$ observed, in patients with periodontal disease, species such as $P$. gingivalis, Eubacterium nodatum, Eubacterium timidum, Eubacterium Brachy, and Peptostreptococcus anaerobius. Corroborating with it, here, Red complex, as well as Green and Orange ones, were detected in higher levels in Pd patients than in control ones, including either diseased or healthy sites. Also, Pd patients harbored higher proportion and/or counts than CG of the following bacteria: A. gerencseriae, S. sanguinis, C. sputigena, P. gingivalis, T. denticola, and T. socranskii. However, we observed that both healthy and diseased sites of $\mathrm{Pd}$ patients presented similar prevalence and counts of bacteria, contradicting findings of a former study which showed that levels of red complex bacteria seem to be related to Periodontitis severity ${ }^{18}$. It is important to note that this study only assessed deep sites ${ }^{18}$. Furthermore, Red complex can be detected in both supra- and subgingival samples as well as in healthy and diseased sites from periodontitis patients ${ }^{7,8}$.

Although the literature suggests that the levels of specific Gram-negative organisms in subgingival plaque biofilm play a major role in the initiation and progression of the disease, there is little evidence in the literature on the correlation of the levels of periodontal pathogens of sites with different pocket depth with periodontal disease activity ${ }^{20}$. 


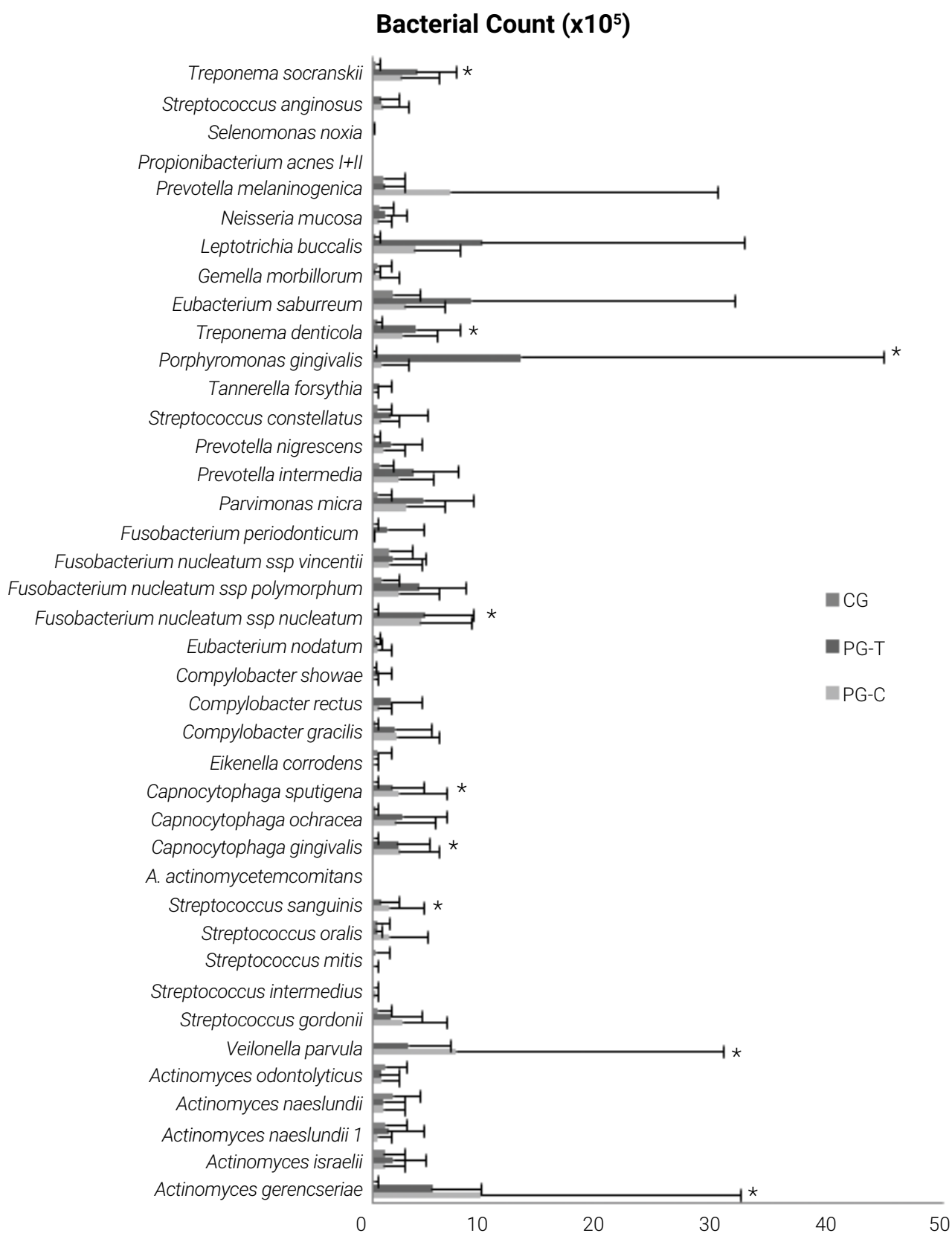

Figure 3. Mean levels (and SD) of the 40 bacterial species evaluated in the three groups (Healthy - Control, CG; Periodontitis - Test, PG-T and Periodontitis - Control, PG-C). Statistically significant differences among groups were evaluated by Kruskal-Wallis followed by Mann-Whitney Test $\left(^{*}\right)$.

Periodontal pathogens are necessary but are not sufficient by themselves to provoke periodontal disease, and depend on risk factors, genetic factors and the immunological response of the host. So, as shown by our study, Periodontitis cannot be strictly considered a site-specific infectious disease but the outcome of a polymicrobial dysbiosis ${ }^{12}$. The microbial ecology is the relationship between the microor- 


\section{Bacterial Complex (Count x 105)}

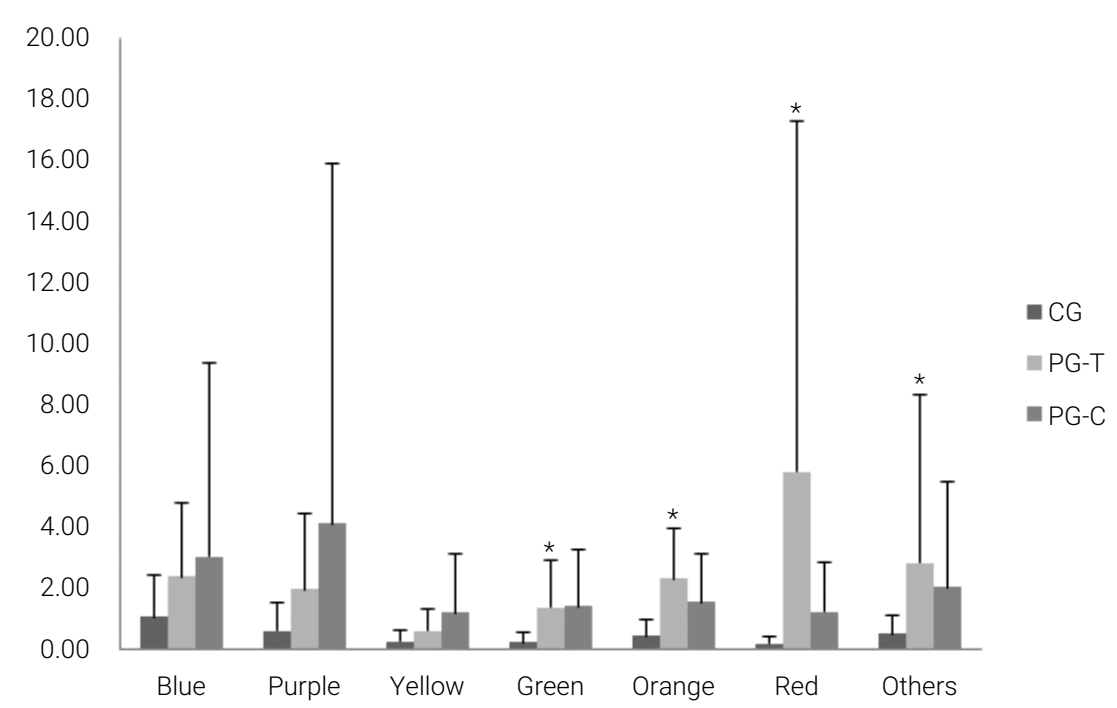

Figure 4. Levels (mean and SD) of bacterial complexes in different groups (Healthy - Control, CG; Periodontitis - Test, PG-T and Periodontitis - Control, PG-C). Statistically significant differences among groups were evaluated by Kruskal-Wallis followed by Mann-Whitney Test $\left(^{*}\right)$.

ganisms and their habitat. Microbial homeostasis is the result of the dynamic balance of microbial interactions, including synergism and antagonism ${ }^{21}$. According to Oliveira et al. ${ }^{22}$ the mere presence of putative periodontal pathogens in the gingival sulcus is not enough to cause periodontal inflammation. The hypothesis that disease can be prevented not only by the inhibition of pathogens but also by interfering with the factors responsible for the transition of commensal biofilm microbiota to pathogenic microbiota, has been postulated ${ }^{23,24}$. Thus, perturbations in the structure of commensal communities (dysbiosis) can lead to a host immune deficiency and the subsequent development of diseases mediated by the immune system. These changes in microbial composition are factors contributing to the initiation and/or persistence of many diseases ${ }^{25-27}$; they are characterized by the loss of beneficial organisms, expansion of potentially pathogenic microorganisms or by the loss of global microbial diversity ${ }^{28,29}$.

The search for the etiological factors of periodontitis, as well as any disease, is related to a dynamic process in which several microbial species dominate the biofilm at different stages of the infection due to changes in nutrient availability, oxygen level, and local $\mathrm{pH}^{24}$. Therefore, the knowledge of the ecological relationships between bacterial species in Periodontitis should direct and focus the research to a critical bacterial interaction ${ }^{30}$, since polymicrobial infectious diseases such as periodontal diseases appear to be caused more by an imbalance of inter-microbial relationship in the subgingival site, as shown in this study, rather than by specific isolated bacteria. So, although Periodontitis is considered a site-specific disease associated with Red complex bacteria, the findings of this study seem to indicate a patient-associated microbial profile rather than a site-specific microbiota. Based on it, the use of sys- 
temic antibiotics in the treatment of periodontal disease may be considered interesting, since it would reduce the presence and number of putative bacteria in the whole oral cavity. Indeed, adjunctive use of metronidazole showed a greater reduction in the levels of periodontal pathogens in Pd patients compared to mechanical control alone $^{31}$. However, it is important to note that good oral hygiene continues to be fundamental in the long-term control of the disease. Poor oral hygiene in Pd patients diminishes the beneficial effects of any treatment ${ }^{32}$.

Although Pd and CG groups were matched by gender to avoid the influence of this factor on the results, this study has some limitations. It is important to highlight the relatively small sample size and the age of subjects. Pd patients were older than clinically healthy ones due to the difficult to find elderly subjects with no signs of periodontitis.

In conclusion, $\mathrm{Pd}$ patients showed higher prevalence and counts of some putative periodontal bacteria, especially from the red complex, than control ones, regardless of the severity of their sites.

\section{Acknowledgments}

We acknowledge the financial support of FAPERJ and FUNADESP.

\section{References}

1. Philstrom BL, Ammons WF. Treatment of gingivitis and periodontitis. Research, science and therapy Committee of the American Academy of Periodontolgy. J Periodontol. 1997 Dec;68(12):1246-53.

2. Hienz SA, Paliwal S, Ivanovski S. Mechanisms of Bone Resorption in Periodontitis. J Immunol Res. 2015;2015:615486. doi: 10.1155/2015/615486.

3. Jarvensivu A, Hietanen J, Rautemaa R, Sorsa T, Richardson M. Candida yeasts in chronic periodontitis tissues and subgingival microbial biofilms in vivo. Oral Dis. 2004 Mar;10(2):106-12.

4. Darby I, Curtis M. Microbiology of periodontal disease in children and young adults. Periodontol 2000 2001;26:33-53

5. Khan SA, Kong EF, Meiller TF, Jabra-Rizk MA. Periodontal Diseases: Bug Induced, Host Promoted. PLoS Pathog. 2015 Jul 30;11(7):e1004952. doi: 10.1371/journal.ppat.1004952.

6. Socransky SS, Haffajee AD. Periodontal microbial ecology. Periodontol 2000. 2005;38:135-87.

7. Socransky SS, Haffajee AD, Smith C, Dibart S. Relation of counts of microbial species to clinical status at the sample sites. J Clin Periodontol. 1991 Nov;18(10):766-75.

8. Ximénez-Fyvie LA, Haffajee AD, Socransky SS. Comparison of the microbiota of supra- and subgingival plaque in health and periodontitis. J Clin Periodontol. 2000 Sep;27(9):648-57.

9. Socransky SS, Haffajee AD, Cugini MA, Smith C, Kent Jr RL. Microbial complexes in subgingival plaque. J Clin Periodontol. 1998 Feb;25(2):134-44.

10. Koshy G, Corbet EF, Ishikawa I. A full-mouth disinfection approach to nonsurgical periodontal therapy - prevention of reinfection from bacterial reservoirs. Periodontol 2000. 2004;36:166-78.

11. Canabarro A, Valle C, Farias MR, Santos FB, Lazera M, Wanke B. Association of subgingival colonization of Candida albicans and other yeasts with severity of chronic periodontitis. J Periodontal Res. 2013 Aug;48(4):428-32. doi: 10.1111/jre.12022. 
12. Camelo-Castillo AJ, Mira A, Pico A, Nibali L, Henderson B, Donos N et al. Subgingival microbiota in health compared to periodontitis and the influence of smoking. Front Microbiol. 2015 Feb 24;6:119. doi: 10.3389/fmicb.2015.00119.

13. Oever JT, Netea MG. The bacteriome-mycobiome interaction and antifungal host defense. Eur J Immunol. 2014 Nov;44(11):3182-91. doi: 10.1002/eji.201344405..

14. Costalonga $\mathrm{M}, \mathrm{Herzberg} \mathrm{MC}$. The oral microbiome and the immunobiology of periodontal disease and caries. Immunol Lett. 2014 Dec;162(2 Pt A):22-38. doi: 10.1016/j.imlet.2014.08.017.

15. Papapanou PN, Sanz M, Buduneli N, Dietrich T, Feres M, Fine DH, et al. Periodontitis: Consensus report of workgroup 2 of the 2017 World Workshop on the Classification of Periodontal and Peri-Implant Diseases and Conditions. J Periodontol. 2018 Jun;89 Suppl 1:S173-S182. doi: 10.1002/JPER.17-0721.

16. Matarazzo F, Figueiredo LC, Cruz SE, Faveri M, Feres M. Clinical and microbiological benefits of systemic metronidazole and amoxicillin in the treatment of smokers with chronic periodontitis: a randomized placebo-controlled study. J Clin Periodontol. 2008 Oct;35(10):885-96. doi: 10.1111/j.1600-051X.2008.01304.x.

17. Lima JA, Santos VR, Feres M, De Figueiredo LC, Duarte PM. Changes in the subgingival biofilm composition after coronally positioned flap. J Appl Oral Sci. 2011 Jan-Feb;19(1):68-73.

18. Farias BC, Souza PR, Ferreira B, Melo RS, Machado FB, Gusmão ES et al. Occurrence of periodontal pathogens among patients with chronic periodontitis. Braz J Microbiol. 2012 Jul;43(3):909-16. doi: 10.1590/S1517-83822012000300009.

19. Moore LV, Moore WE, Cato EP, Smibert RM, Burmeister JA, Best AM et al. Bacteriology of human gingivitis. J Dent Res. 1987 May;66(5):989-95.

20. Dosseva-Panova VT, Popova CL, Panov VE. Subgingival microbial profile and production of proinflammatory cytokines in chronic periodontitis. Folia Med (Plovdiv). 2014 Jul-Sep;56(3):152-60.

21. Hajishengallis G. Periodontitis: from microbial immune subversion to systemic inflammation. Nat Rev Immunol. 2015 Jan;15(1):30-44. doi: 10.1038/nri3785.

22. Oliveira LF, Jorge AOC, Santos SS F. In vitro Minocycline Activity on Superinfecting Microorganisms Isolated from Chronic Periodontitis Patients. Braz Oral Res. 2006 Jul-Sep;20(3):202-6.

23. Takahashi N. Oral Microbiome Metabolism: From "Who Are They?" to "What Are They Doing?". J Dent Res. 2015 Dec;94(12):1628-37. doi: 10.1177/0022034515606045.

24. Kolenbrander PE, Egland PG, Diaz PI, Palmer RJ Jr. Genome interactions: bacterial communities in initial dental plaque. Trends Microbiol. 2005 Jan;13(1):11-5.

25. Frank DN, St Amand AL, Feldman RA, Boedeker EC, Harpaz N, Pace NR. Molecular-phylogenetic characterization of microbial community imbalances in human inflammatory bowel disease. Proc Natl Acad Sci U S A. 2007 Aug 21;104(34):13780-5.

26. Karlsson FH, Tremaroli V, Nookaew I, Bergström G, Behre CJ, Fagerberg B et al. Gut metagenome in European women with normal, impaired and diabetic glucose control. Nature. 2013 Jun 6;498(7452):99-103. doi: 10.1038/nature12198.

27. Abrahamsson TR, Jakobsson HE, Andersson AF, Björkstén B, Engstrand L, Jenmalm MC. Low gut microbiota diversity in early infancy precedes asthma at school age. Clin Exp Allergy. 2014 Jun;44(6):842-50. doi: 10.1111/cea.12253.

28. Petersen C, Round JL. Defining dysbiosis and its influence on host immunity and disease. Cell Microbiol. 2014 Jul;16(7):1024-33. doi: 10.1111/cmi.12308.

29. Gootz TD. The global problem of antibiotic resistance. Crit Rev Immunol. 2010;30(1):79-93.

30. Ng HM, Kin LX, Dashper SG, Slakeski N, Butler CA, Reynolds EC. Bacterial interactions in pathogenic subgingival plaque. Microb Pathog. 2016 May;94:60-9. doi: 10.1016/j.micpath.2015.10.022. 
31. Soares GM, Mendes JA, Silva MP, Faveri M, Teles R, Socransky SS et al. Metronidazole alone or with amoxicillin as adjuncts to non-surgical treatment of chronic periodontitis: a secondary analysis of microbiological results from a randomized clinical trial. J Clin Periodontol. 2014 Apr;41(4):366-76.

32. Mdala I, Olsen I, Haffajee AD, Socransky SS, de Blasio BF, Thoresen M. Multilevel analysis of bacterial counts from chronic periodontitis after root planing/scaling, surgery, and systemic and local antibiotics: 2-year results. J Oral Microbiol. 2013 Jul 9;5. doi: 10.3402/jom.v5i0.20939. 